\title{
Shining examples analysed within the EBC Annex 56 project
}

\author{
Ove Mørck $^{\mathrm{a}, *}$, Manuela Almeida ${ }^{\mathrm{b}}$, Marco Ferreira ${ }^{\mathrm{b}}$, Nelson Brito ${ }^{\mathrm{c}}$, \\ Kirsten Engelund Thomsen ${ }^{\mathrm{d}}$, Iben Østergaard ${ }^{\mathrm{e}}$ \\ a Cenergia Energy Consultants, Herlev Hovedgade 195, Herlev 2730, Denmark \\ b University of Minho, Azurém, 4800-058 Guimarães, Portugal \\ c ISR-UC, ADAI-LAETA, modular, Coimbra 3000-288, Portugal \\ d Danish Building Research Institute, SBi, Aalborg University Copenhagen, Copenhagen SV 2450, Denmark \\ e Danish Technological Institute, Taastrup 2630, Denmark
}

\section{A R T I C L E I N F O}

\section{Article history:}

Received 31 October 2015

Received in revised form 8 March 2016

Accepted 29 May 2016

Available online 4 June 2016

\section{Keywords:}

Energy renovation

Residential buildings

Energy savings

Reduction of carbon emissions

\begin{abstract}
A B S T R A C T
The International Energy Agency established an Implementing Agreement within the Energy in Buildings and Communities Program to undertake research and provide an international focus on "Cost Effective Energy and Carbon Emissions Optimization in Building Renovation" (EBC Annex 56). The project aims at developing a new methodology to enable cost effective renovation of existing buildings while optimizing energy consumption and carbon emissions reduction. Several case studies were gathered to develop and validate the methodology, and a selection of "Shining Examples" was made to encourage decision makers to promote efficient and cost effective renovations. This paper presents the results of the analyses made on these Shining Examples.

Highlights:
\end{abstract}

- Several building renovation projects were gathered within EBC project Annex 56.

- Optimization of costs, energy and emissions requires flexible approaches.

- Combination of energy efficiency measures and renewable energy is necessary.

- Solutions depend of local opportunities and constraints, ownership and local laws.

- Benefits of the renovation measures go beyond functionality and energy savings.

(c) 2016 Elsevier B.V. All rights reserved.

\section{Introduction}

Worldwide nations are gathering efforts in an attempt to mitigate the climate changes. Despite the commitments assumed in the Kyoto protocol, in the current patterns of energy consumption and consequent carbon emissions, the established targets will not be achieved [1].

Within the European Community, the building sector has been identified as one of the largest energy consumers, responsible for $40 \%$ of the final energy use and $35 \%$ of the carbon emissions [2]. In face of these numbers, the interest on the potential of improving buildings energy performance has arisen, especially in existing buildings and particularly in residential buildings that represent $75 \%$ of the European total building stock [3]. The potential of

\footnotetext{
* Corresponding author.

E-mail addresses: ocm@cenergia.dk (O. Mørck), marcoferreira@civil.uminho.pt (M. Ferreira).
}

improving building energy performance is often missed, mainly due to the lack of know-how and information on the issue and financial and political difficulties related to building renovation [1].

In an attempt to mitigate the climate changes and concerning the political actions, the European Commission has created some initiatives such as the Europe 2020 strategy, where the Commission has set targets related to energy and carbon emissions to be accomplished until 2020, of reducing in $20 \%$ the carbon emissions, increase the energy efficiency by $20 \%$ and increase in $20 \%$ renewable energy use [4].

In the meantime the European Commission has revised the targets related to the share of carbon emissions that come from residential buildings and aims at reducing the emissions in $40 \%$ when compared to the levels of 1990, until 2030. These targets are being set with the aim of achieving in a cost-effective way the objective set to 2050 , of reducing $80 \%$ of the carbon emissions [5].

Concerning the European policies, many regulations have become more demanding, but the turning point on the path towards more efficient building stock was the EPBD recast, where 
it is noteworthy the introduction of two fundamental concepts: cost-optimality and the nearly Zero Energy Buildings (nZEB) [4]. The cost-optimal concept emphasises the need of establishing cost/performance levels suitable to each Member State context, while the nZEB balance is focused on high energy performances with low energy needs that should be fulfilled with renewable energy sources harvested on-site or nearby [4]. Although these two approaches are focused on different aspects, they are related, and it is expected that the gap between them might be reduced during the next few years mainly supported by the improvement of the cost-effectiveness of systems based on renewable energy [6,7].

These two concepts are focused on new buildings and require measures for energy conservation and energy efficiency that may involve significant investments on the buildings envelope and production of on-site energy from renewable sources [8].

Taking actions just on new buildings is not enough to achieve the carbon emissions reduction and energy targets, given the low rates of replacement of the existing building stock in Europe [9]. Moreover, the application of the current standards established for new buildings to the existing buildings may lead to the increase of costs which is not very well accepted by the decision makers in a renovation process [10].

In order to help managing this mismatch related to the application of the current standards to existing buildings, IEA EBC launched in 2010 the project Annex 56-Cost Effective Energy and Carbon Emissions Optimization in Building Renovation. The project (ending in December 2015) involves eleven European participating countries and China, and investigates the range of cost effective renovation measures that, increasing energy efficiency and the deployment of renewable energy, achieve the best building performance at the lowest effort. Concerning the reduction of carbon emissions in buildings, renewable energy supply measures can be as effective as energy conservation and energy efficiency measures, but the balance between these measures may vary from building to building, given the contextual, physical, technical and economic differences. Thus, the project studied how far the energy conservation and efficiency measures should go and when the renewable energy sources become more economic. Besides this, investigations on how the co-benefits (or additional benefits) that can be achieved in an energy renovation intervention can be taken into account in the decision-making process are also part of the objectives of the project [8]. The co-benefits are difficult to monetise and for that reason they are often undervalued, which may represent a missed opportunity to go beyond the cost-optimal levels towards better energy performances in a cost effective way, reducing more effectively the carbon emissions.

In this context, the methodology created allows accessing costs, energy and carbon emissions and the impact of the renovation measures using parametric calculations on some generic virtual buildings (representative of the building stock of each participating country) and on the case studies provided by the participating countries. The methodology comprises Initial Investment Costs (IIC), Life Cycle Costs (LCC) evaluated in a 30 years period, Life Cycle Impact Assessment (LCIA) and co-benefits assessment of cost effective energy related renovation measures. Besides the methodology, the project also aims to support and motivate decision-makers and experts with scientific information for their future decisions, based on the analysis of different case-studies that proved to be successful renovation projects, which have been analysed in two different levels: the "Detailed Case Studies" and the "Shining Examples" [1].

This paper presents conclusions driven from the Shining Examples that were selected to encourage decision makers and to promote efficient and cost effective renovation processes. With the Shining Examples it is expected to highlight advantages and innovative solutions and strategies in building renovation. These examples also allowed identifying the barriers faced in each exam- ple, the solutions found to overcome those barriers and also the co-benefits that come from renovation measures [11].

\section{Shining examples collected}

The Case Studies within Annex 56 project were studied at two different levels. Level 1-the "Shining Examples" and level 2-the "Detailed Case Studies", as mentioned before. Within level 1, a selection of "Shining Examples" to encourage decision makers to promote efficient and cost effective renovations is provided. In level 2 , a deeper analysis is performed in order to evaluate the impact and relevance of different renovation measures and strategies within the project.

The "Shining Examples" are gathered mainly for motivation and stimulation purposes, highlighting the advantages of the energy and carbon emissions cost optimized renovation and the innovative (but feasible) solutions and strategies performed.

The compilation of Shining Examples has been documented in a "brochure", which presents the Shining Examples in a fixed format showing for each project pictures and easily comprehensible graphics, highlighting the added-value of the renovation process. The brochure published by the project [11] presents 18 Shining Examples from 9 countries. Table 1 presents an overview of the collected Shining Examples.

\section{Analyses of Shining examples}

A cross-section analysis of the shining examples has been carried out to identify similarities, differences and general findings. The results of this analysis are presented in 5 sections covering: barriers/solutions, anyway measures, rational use of energy/renewable energy supply (RUE/RES) balance of measures, co-benefits and country/climate specific measures.

\subsection{Barriers/solutions}

The implementation of energy renovation projects in the building sector is not just a technical and/or economical matter. It involves the users/inhabitants/owners of the buildings, which, in some cases, have to leave the buildings for a shorter or longer period. Additionally, those who pay for the energy renovation are not always those who benefit from it. Therefore, energy renovation projects often run into barriers that may hold up the project. It is then necessary that owners, technical consultants and policy makers find solutions to overcome these barriers. In a pre-study on barriers and solutions carried out in the context of this work, four different categories of barriers were identified:

- Information issues;

- Technical issues;

- Ownership issues;

- Economic issues.

The information issues can be either confusing information, i.e. different opinions expressed by different professionals, or incomplete information. It can also be lack of clear requirements, lack of inspiration or lack of knowledge about possibilities, potential benefits and added values. The technical issues are mainly related to lack of well proven systems and lack of complete solutions consisting of packages of technologies. The ownership issues generally have to do with who has to pay for the investment in energy renovations and who saves the money-not always the same person(s). The economic issues can be as simple as too high investments needed, which often are also coupled with lack of incentives. Additionally, there may be uncertainty as to how much money can be saved from 
Table 1

The 18 Shining Examples collected and documented.

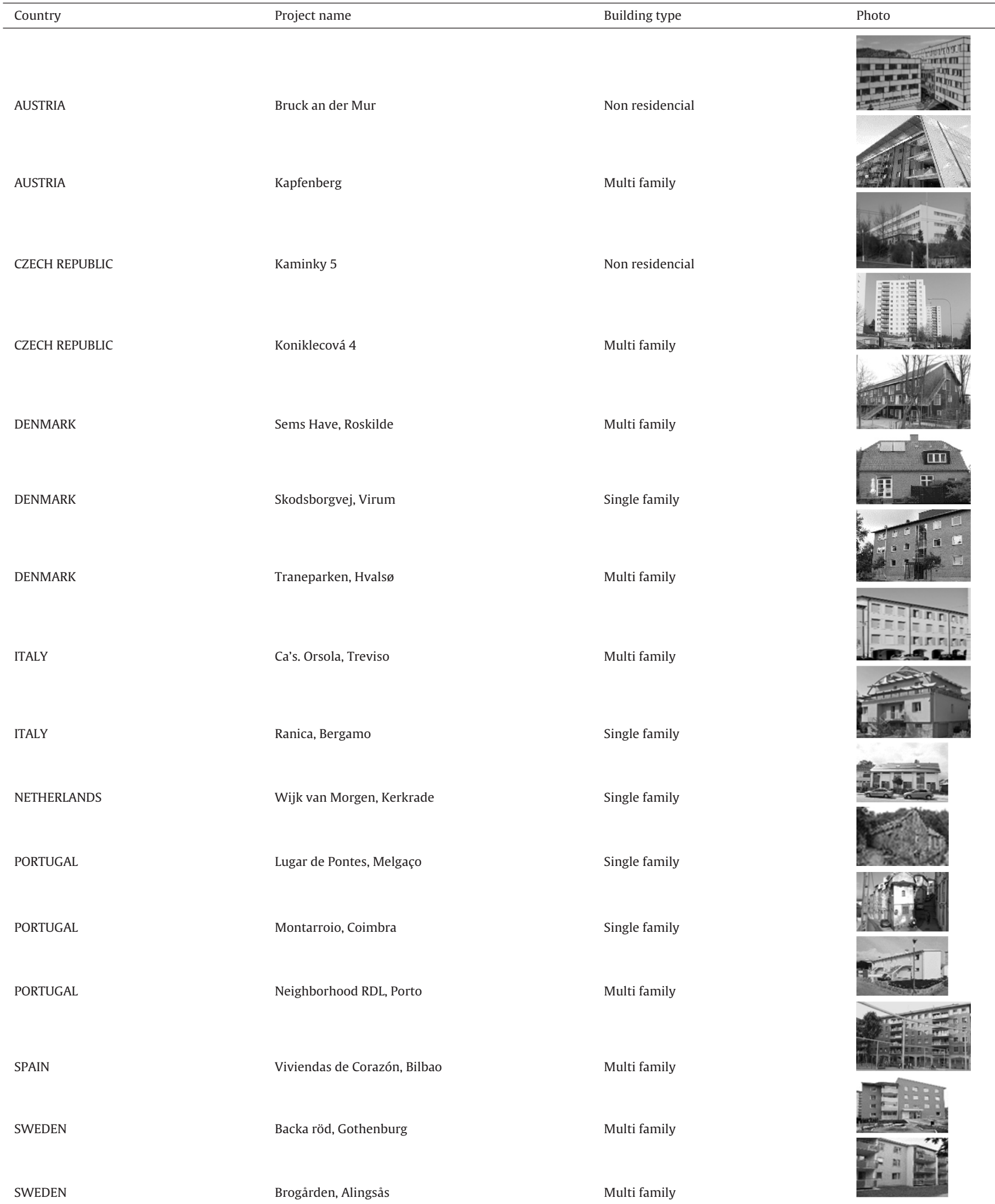


Table 1 (Continued)

\begin{tabular}{|c|c|c|c|}
\hline Country & Project name & Building type & Photo \\
\hline SWEDEN & Maratonvagen, Halmstad & Multi family & \\
\hline SWITZERLAND & Les Charpentiers, Morges & Multi family & \\
\hline
\end{tabular}

the energy renovation (sometimes just the comfort is improved) and finally, lack of economic understanding or knowledge.

The analysis reveals that the barriers met were sometimes a combination of different kinds of barriers including information, economic and ownership/user issues. Tenants in rented apartments are often in focus as critical elements in the renewal process as for example in the Swiss case, where it was important to keep the largest possible number of tenants in their apartments during the renovation. In Denmark, tenants came into play in a different way as the democratic requirements in the Danish housing rent laws demand that tenants vote for the energy renovation before it can be initiated.

In Portugal, the financing was a barrier in all cases and the lack of knowledge by some stakeholders, and different opinions among involved partners, were issues to deal with. In all cases, the solutions found to overcome the barriers met were quite straightforward and can be summarized in one word: "perseverance". Many of these projects could not have been implemented if a single person or team had not taken ownership of the project and had fought for their completion.

The overall conclusion from the analysis of the 18 Shining Examples is that for 7 of these there were apparently no barriers worth mentioning. For 7 of them, the barriers were mainly of administrative matter-for example delay caused by poor project leadership. For 6 of the cases, the economical/financing issues created barriers causing problems and delays. This conclusion differs somehow from the result of a questionnaire carried out earlier among the participants in this project where the lack of information and lack of economic incentives were mentioned as barriers for, respectively, all of the case-studies that answered the questionnaire at that time. This may be explained by the fact that these are general barriers, which block the carrying through of energy renovation projects, whereas in the 18 Shining Examples presented here they were obviously overcome.

The Shining Examples documented may be characterized as forerunners and therefore not typical energy renovation projects, which may explain the fact that only few of the general barriers identified in the questionnaire are represented.

\subsection{Anyway measures}

The expression "anyway measures" was chosen to highlight the inevitability of the costs associated to maintaining, extending or replacing materials, equipment and systems to keep the building fully functional, or to make it contemporary with impending mandatory regulations, yet do not improving the energy performance of the building, nor deploying additional energy from renewable sources.

In order to adequately perform comparisons between "Cost Effective Energy and Carbon Emissions Optimization in Building Renovation" packages of renovation measures and a reference scenario are needed.

Having in mind that the optimization costs include all expenses related to implementing the measures and related procedures (soft costs), it is fair to assume "anyway measures" costs deductable from this total investment, as they would occur anyway without optimization. In fact, these "anyway measures" can be triggers for intervention [12], as demonstrated later.

The scope of the "anyway measures" tag includes all the costs that would naturally occur during the expected lifetime of the building and without which failure would occur. Well performed "anyway measures" increase or maintain the existing building value, and the same can be achieved by well performed optimization interventions. The "anyway measures" considered in this analysis included all the costs that the proposed optimization measures are able to substitute or defer in the existing building operational and maintenance requirements, and subsequently differ from country to country and from building to building, according to the specific context of each of them.

One example is the insulation of external walls, applied in all the "Shining Examples" with exception of the Montarroio case study due to contextual and conceptual requirements, although calculated in two options to allow comparisons. External walls require "anyway measures" that range from regular condition verifications to periodic paintings or substitution due to wear and tear. The "anyway measures" costs, those that would happen anyway, account for scaffolding or other lifting methods to execute the work, workmanship, materials and soft costs: after whatever intervention, the aesthetics is improved or maintained and the value of the building increases, or at least does not decrease. So, an optimization measure using external insulation will need the same scaffolding or other lifting methods to execute the work, some of the workmanship and a few similar materials. This means that the optimization measure costs can then be calculated accounting all the expenses directly related to the optimization measure, subtracted by the values that would occur in the "anyway measures".

The Shining Examples show that the need for renovation or maintenance-the need for the "anyway measures"-created most of the opportunities for energy efficient renovation and renewable energies introduction.

Anyway, it is relevant to note that in programmed change situations it would be fair to assume that "anyway measures" can consider recent solutions that represent the local trends: if an efficient and renewable based district heating system is available, it is natural to consider that a building system renovation would use the almost carbon free network solution. In rupture related situations, "anyway measures" consist frequently in exchanging the existing system by an equivalent one, that will only be more efficient due to the normal evolution of equipment, regulations and certification processes: thus the importance of preparing owners to acknowledge the alternatives long before rupture.

\subsection{Which measures (RUE/RES balance)}

When tackling energy consumption reduction in existing building renovation, two major approaches (often combined in one project) describe most of the options: those that reduce energy consumption, associated to a Rational Use of Energy (RUE), and those related to supplying the existing needs with Renewable Energy Sources (RES). 
Many of the Rational Use of Energy (RUE) measures are currently less expensive while including the advantage of reducing the energy that has to be supplied by Renewable Energy Sources (RES), although further evolution in the existing or innovative technologies may alter this cost relation.

In several of the Shining Examples, energy consumption reductions (RUE) were achieved by improving the performance of the building envelope and recovering heat from the ventilation losses, and for others significant use of solar panels or renewable-based district heating (RES) was used to complement the remaining needs. What both show is that each combination is a direct result from the existing context, the available solutions and sources, and significant integration efforts. Depending on the climate severity, period/quality of construction and many other factors (see topic Barriers) the buildings behave differently, create different baselines and require different intervention strategies.

Many of the RUE measures included the renovation of the boundaries with poor thermal performance (roofs, ceilings, walls, windows and floors with insufficient or no insulation), with particular focus on those in need of renovation due to wear and tear (see topic "Anyway measures"). The improvement of energy conservation noticed in roofs ranged from $65 \%$ to $95 \%$, while in the walls it ranged from $50 \%$ to $90 \%$. It is important to notice that in walls the U-values after renovation vary from $0.45 \mathrm{~W} /\left(\mathrm{m}^{2} \mathrm{~K}\right)$ in warmer climates to $0.11 \mathrm{~W} /\left(\mathrm{m}^{2} \mathrm{~K}\right)$ in more severe ones, while in roofs, the values ranged from $0.64 \mathrm{~W} /\left(\mathrm{m}^{2} \mathrm{~K}\right)$ to $0.08 \mathrm{~W} /\left(\mathrm{m}^{2} \mathrm{~K}\right)$, in the same situations. In the particular case of windows, the improvements ranged from $15 \%$ to $75 \%$, where countries and specific locations with higher demands for heating demonstrate the use of a wider range of high performance windows (triple glazing is rather common).

In most of the examples, the RUE measures were taken as a first step to reduce the energy demand while improving the occupants' comfort (see topic "Co-benefits"), while reducing the amount needed from RES production. The Renewable Energy Sources approach was implemented in most of the buildings either by connecting to existing district heating structures fuelled by biomass or garbage combustion, or using biomass based heating systems. Many Shining Examples also included solar thermal panels for domestic hot water and/or heating or solar photovoltaic (PV) panels for consumption or connection to the grid.

\subsection{Co-benefits}

Several terms are used in the literature for side-effects that arise from building renovation such as co-benefits, non-energy benefits (NEBs) and multiple benefits. In Annex 56 it is used the term cobenefits to include all effects of energy related renovation measures besides reduction of energy, carbon emissions and costs. These cobenefits can have a significant value but are most often disregarded being the reason for the underestimation of the full value of the renovation works.

In Annex 56 the following co-benefits are considered: 1) Thermal comfort, 2) Natural lighting and contact with the outside environment, 3) Improved air quality, 4) Reduction of problems with building physics, 5) Noise reduction, 6) Operational comfort, 7) Reduced exposure to energy price fluctuations, 8) Aesthetics and architectural integration, 9) Useful building areas, 10) Safety (intrusion and accidents), 11) Pride, prestige, reputation and 12) Ease of installation.

An analysis for the valuation and integration of co-benefits in the decision making process performed under a private perspective (from user/promoter/owner point of view), and in this process it was therefore relevant to identify and evaluate all the effects that arise from different renovation measures.

In fact, one of Annex 56 goals was to evaluate possible forms of integrating co-benefits in the methodology for cost effective energy and carbon emissions optimization, but practice demonstrated that these benefits are often difficult and nearly impossible to quantify and measure accurately, which makes it much more difficult to add their contribution into a traditional cost-benefit analysis. Considering these constraints, a matrix of relationships between co-benefits and specific renovation measures has been developed, indicating for each renovation measure, not only the co-benefits that usually occur as a consequence of that intervention, but also its relevance. The relevance of the co-benefits is presented in the matrix for the average and most common situation, but this guidance is to be complemented by the consideration of additional factors which may change relevance of co-benefits in a particular and specific renovation process. This method is intended to be used by owners and promoters during the decision-making process, so that they can be fully aware of the co-benefits of each possible renovation measure and compare different renovation packages also considering the related co-benefits.

Some of the co-benefits occur as a consequence of reduction of energy consumption, carbon emissions and costs respectively while others occur as a side effect of the renovation measures (e.g. less noise after changing windows). Many factors determine whether occupants find energy renovation to be successful, and the co-benefits in the Shining Examples include a big variety of parameters like better indoor climate, comfort and architecture. Besides, most of the Shining Examples have been initiated without having the reduction of the energy demand as a priority, so the energy renovation was most often an addition to an anyway renovation of the buildings.

Nevertheless it was noticed that some of the positive experiences identified in the co-benefits range that were communicated to building owners or tenants helped to overcome barriers that homeowners and housing associations were experiencing, which validates their real value.

\subsection{Country/climate specific measures}

The energy renovation technologies implemented in the Shining Examples have been systemized according to the country or climate. All cases have had insulation added, most of them on façades and roofs. 17 cases have included new energy efficient windows in the renovation, being the Montarroio case study in Coimbra the exception on the basis of contextual UNESCO site restrictions [13], scientific knowledge [14] and dynamic simulation [15].

Solar heating is exploited either in an active or passive way in 10 of the cases. In most of the cases the heating system was renovated and/or supplemented with renewable energy systems.

A summary of the energy renovation features follows:

- All examples carried out insulation of the envelope in one way or another. One Austrian and one Swiss example have changed the facade with new facade elements including active and passive elements or added an extra module for passive solar use;

- 17 examples have changed windows or glazing;

$\bigcirc$ Southern European countries typically use double layerglazing, where central and northern Europe use triple layer glazing;

- 14 examples have ventilation with heat recovery;

- Half (9) of the examples have solar thermal features mainly for domestic hot water;

- 7 cases have installed PV-plants-only one of them in southern Europe;

- Half of the cases have improved their lighting by LED or other efficient light; 
- Half of the cases have new or improved heat distribution systems such as thermostatic valves, insulation of tubes or implemented individual meters;

- 13 of the 18 examples have changed or improved their heat supply: three of the examples have solar heating as heating supplement;

- Four heat pumps have been installed:

$\bigcirc$ Two have installed water-to-water (ground coupled) heat pumps;

- One example has a reversible heat pump with boreholes for cooling in the summer and heating in the winter;

- One example has air-to-air heat pump (also working as air conditioning system);

- Four new gas boilers were installed and one example has a gas driven CHP system;

- Two have installed wooden stoves for heating and either cooking or domestic hot water, and one has biomass district heating;

- One has installed a new district heating substation connection;

- Three examples have implemented some kind of cooling system:

$\bigcirc$ In Lugar the Pontes, Melgaço, Portugal, where the summer is quite hot, a "classic" air conditioning system was necessary. In this case, the window area has been increased, improving the use of daylight and increasing heat gains, which are useful during winter. On the other hand, the increase in window area lead summer to higher heat gains, while the reduced inertia factor resulting from the insulated walls results in higher cooling needs. In this case, the heat recovery of the ventilation air has not been applied due to the low savings potential because of the relative mild winter in this region of Portugal.

- In Montarroio, Coimbra, Portugal, excess heat production by the summer season "over dimensioned" solar thermal panels is channelled to a small adsorption unit to produce ice at night for daily cooling needs [13].

- A cooling/heating system in Austria consists of a reversible heat pump with deep drillings to cool in summer and heat in winter.

\section{Results-energy savings}

An analysis of the energy consumption before and after energy related renovations has been carried out in order to provide an overview of the impact of the energy saving strategies implemented or anticipated. This has been done in the following way: the energy consumption before the renovation was evaluated (in some cases with monitoring while others based on calculations considering the original energy performance of the buildings), the impacts of RUE measures in energy savings and the contribution of renewable energy (RE) was estimated and the final net energy consumption was mapped and all compared in histograms. Thereby it is possible to evaluate the impact of implementing the RUE technologies and the RE technologies contributions separately and together. The analysis also included an attempt to find out if the energy savings have a climate/location dependent pattern.

The energy savings of the Shining Examples are presented for three groups of buildings: Public buildings (schools \& offices), single family buildings and multifamily buildings.

\subsection{Public buildings}

Only two public buildings are studied: the elementary school located in Kaminky, Czech Republic and the federal Ministry of Justice of Bruck/Mur in Austria. Both present a fairly high energy reduction by the incorporation of RUE by a $63 \%$ and $83 \%$ for the School and the Official building respectively, as it can be seen from Fig. 1.
Although only two non-residential buildings have been included in this group, all the analysis performed during the project indicate that main conclusions are identical between residential buildings and office buildings without complex building integrated technical systems.

\subsection{Single-family buildings}

Four single-family buildings were analysed, two of them from Portugal, one from Italy and one from Denmark. See Fig. 2.

By the foreseen use of RUE and RE technologies, Montarroio, PT becomes a "nearly Zero Energy Building". Solar thermal and biomass energy supply $95 \%$ of the heating and DHW demand after the energy renovation.

Via Trento from Italy and Lugar de Pontes from Portugal present a considerable heating consumption reduction of $93 \%$ and $90 \%$, respectively, after the RUE renovation. In addition, solar thermal collectors have been incorporated to the building reducing the heating consumption by additional $33 \%$ and $43 \%$.

The single family house from Denmark shows a heating energy reduction of only $42 \%$ after renovation and in addition $10 \%$ more is reduced by the incorporation of solar thermal collectors.

\subsection{Multifamily houses}

The Shining Examples are predominantly multifamily buildings. The 11 projects are shown in Fig. 3. The most remarkable heating energy consumption reduction is seen in Switzerland: $83 \%$ is reached by the integration of a passive solar façade and a new gas cogeneration system.

Among the Shining Examples located in the South of Europe, Ca's. Orsola in Italy presents a heating energy reduction from RUE by $77 \%$. The heating demand is provided by geothermal and solar thermal systems. In addition, the building has been equipped with a PV electrical contribution of $3.7 \mathrm{kWh} / \mathrm{m}^{2}$. The building from Spain stands out by its low energy RUE and RE reduction, since only 50\% of the DHW consumption is supplied by a solar thermal system.

The highest percentage of solar energy contribution, both Solar thermal and PV electrical, is found in Kapfenberg, Austria, reducing $48 \%$ the total energy consumption after energy renovation by RUE.

The Shining Examples in Sweden and the Check Republic do not have any RE-system added to the building. However, the total energy consumption has decreased by over $50 \%$ by the energy renovation of the building envelope and adding efficient ventilation and lighting features.

\subsection{Overall energy savings by RUE and RE}

For most of the Shining examples the energy reduction reached by implementing RUE technologies lies between $40 \%$ and $83 \%$-extremes are $16 \%$ and $90 \%$. The RE contribution to the remaining energy demand lies between $7 \%$ and $47 \%$-extremes being $0 \%$ and $90 \%$. The total energy reductions achieved by the combination of RUE and RE technologies are between $40 \%$ and $95 \%$. Here the extremes are $29 \%$ and $98 \%$.

\section{Conclusions}

This paper presents some renovation examples that are useful as depictions of built realities that, through different approaches, consolidate the topics under analysis in the scope of Annex 56. This small illustration of "Shining Examples" demonstrates that a "one size fits all" approach is unviable in the diversity of contexts where a "Cost Effective Energy and Carbon Emissions Optimization in Building Renovation" is needed. Case by case these examples show that the implemented RUE/RES measures were a consequence of local 


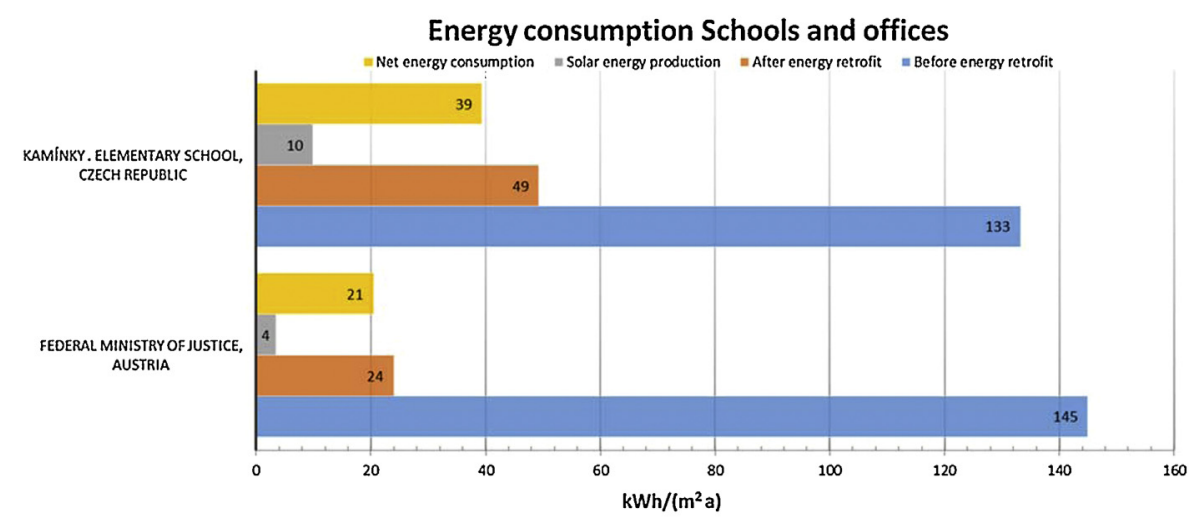

Fig. 1. Overview of the energy consumption before and after energy retrofit for the two public building cases.

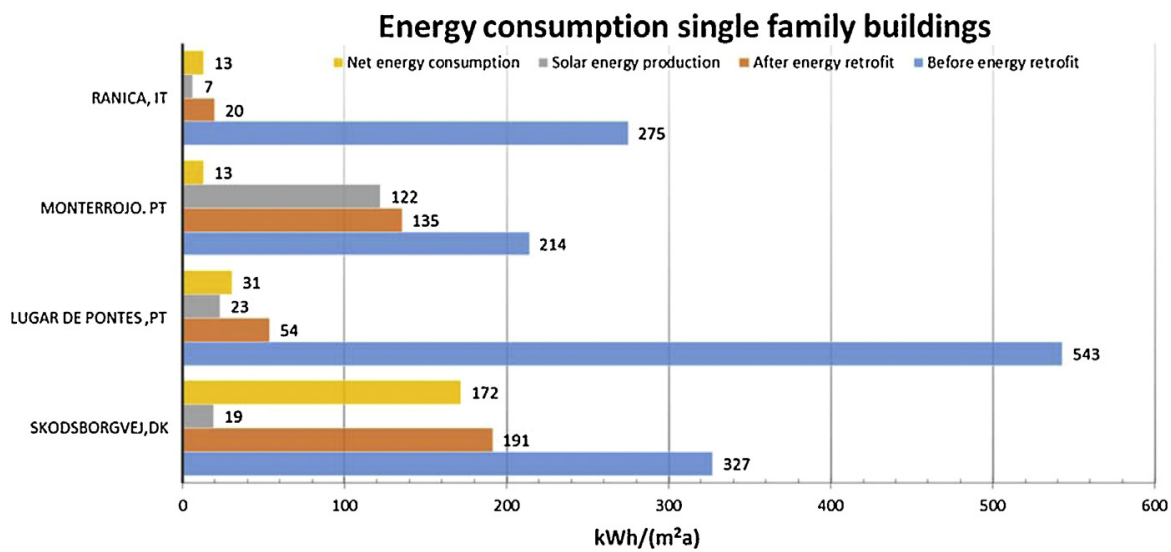

Fig. 2. Overview of the energy consumption before and after energy retrofit for the four single-family buildings.

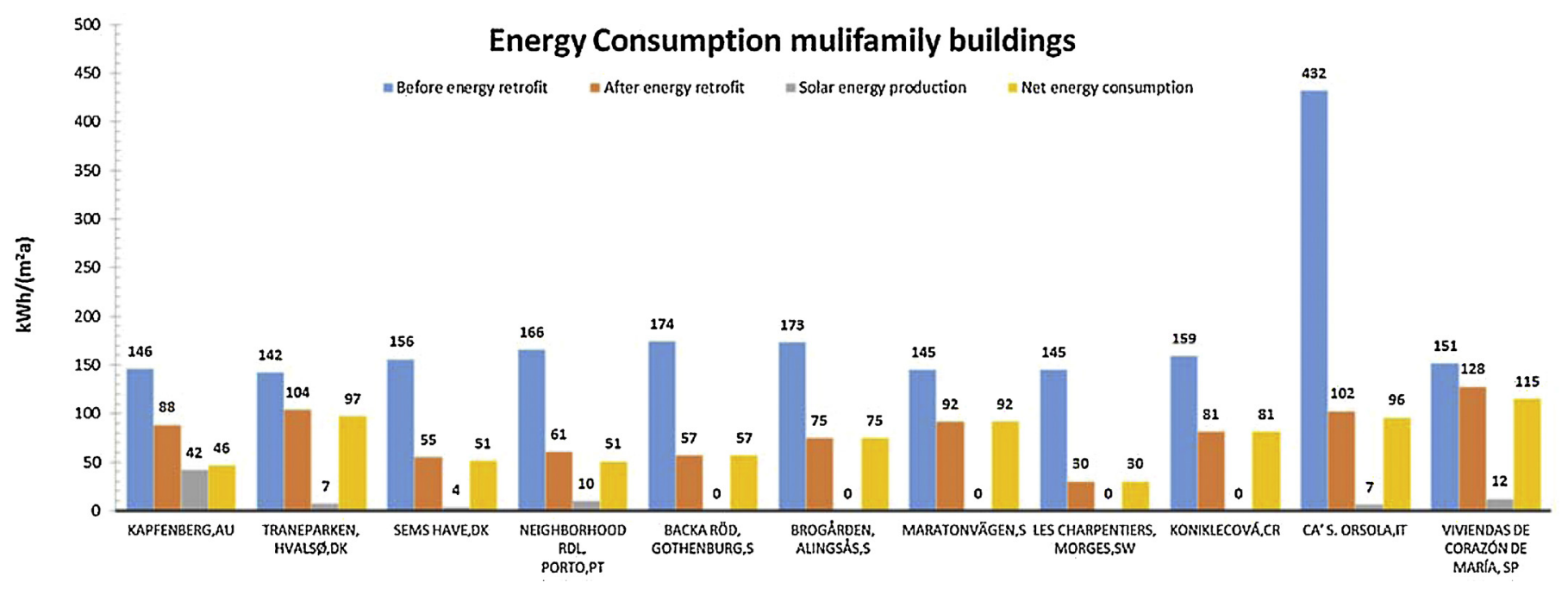

Fig. 3. Overview of the energy consumption before and after energy retrofit of multifamily buildings.

opportunities and constraints, ownership and local laws, and not only a design option.

The Shining Examples documented may be characterised as forerunners initiated by "first movers", and therefore the experiences documented may be somewhat different from what other new renovation project may meet.

However, the multidisciplinary design approach of these examples demonstrates the potential of the renovation measures beyond functionality and energy consumption reduction. As a whole they state that this potential can be harnessed in all the scope of existing buildings renovations, from single family to multi-family buildings, with the appropriate adaptations to each context.

The aim of the EBC Annex 56 on "Cost Effective Energy and Carbon Emissions Optimization in Building Renovation" is to provide designers with the examples and tools to illustrate the possible solutions-where several alternatives and options are interrelated in each building specific context. 


\section{Acknowledgements}

The work of the participants of IEA EBC Annex 56 compiling the information for the Shining Examples and the analyses performed is greatly appreciated.

The work within IEA EBC is co-funded by different national authorities and the individually participating national organisations-universities and private companies. Without their contributions, this work had not been possible.

\section{References}

[1] W. Ott, R. Bolliger, V. Ritter, S. Citherlet, D. Favre, B. Perriset, M. Almeida, M. Ferreira, (2014). Methodology for Cost-Effective Energy and Carbon Emissions Optimization in Building Renovation (Annex 56) - Methodology and Assessment of Renovation Measures by Parametric Calculations. Energy in Buildings and Communities Programme of the International Energy Agency, Edited by University of Minho; Guimarães, Portugal, ISBN: 978-989-95961-6-0.

[2] Buildings Performance Institute Europe, Implementing Cost-Optimal Methodology in EU Countries - lessons learned from three case studies, 2013, Brussels, Belgium, ISBN: 9789491143083.

[3] Buildings Performance Institute Europe, Europe's buildings under the microscope - a country-by-country review of the energy performance of buildings, 2011, Brussels, Belgium, ISBN: 9789491143014.

[4] European Parliament and the Council of European Parliament, Directive 2010/31/EU of the Parliament and of the Council of 19 May 2010 on the energy performance of building (recast), Off. J. Eur. Union (2010).

[5] European Commission, Communication from the Commission to the European Parliament, the Council, the European Economic and Social Committee and the Committee of the Regions-A Policy Framework for Climate and Energy in the Period from 2020 to 2030. Brussels 22/1/2014, 2014 (available at:) http://ec.europa.eu/clima/plicies/2030/documentation_en.htm.

[6] M. Ferreira, M. Almeida, A. Rodrigues, S. Silva, Comparing cost-optimal and net-zero energy targets in building retrofit, Build. Res. Inf. (2014), http://dx. doi.org/10.1080/09613218.2014.975412.
[7] M. Ferreira, M. Almeida, A. Rodrigues, Cost optimality and net-zero energy in the renovation of Portuguese residential building stock-Rainha Dona Leonor neighborhood case study, Int. J. Sustain. Build. Technol. Urban Dev. (2014)

[8] Energy Conservation in Buildings and Community Systems Programme of the International Energy Agency, ECBCS News June 2012-Issue 55, pp. 9-10, 2012, Birmingham, United Kingdom, ISSN 1023-5795.

[9] N.S. Brito, M.C. Gameiro da Silva, Upgrade opportunities for buildings in city centres, EPJ Web Conf. 33 (2012) 05008, http://dx.doi.org/10.1051/epjconf/ 20123305008 .

[10] F. Bartiaux, K. Gram-Hanssen, P. Fonseca, a.L. Ozolin, T.H. Christensen, A practice-theory approach to homeowners' energy retrofits in four European areas, Build. Res. Inf. 42 (4) (2014) 525-538, http://dx.doi.org/10.1080/ 09613218.2014.900253.

[11] Ove Christen Mørck et.al., Shining Examples of Cost-Effective Energy and Carbon Emissions Optimization in Building Renovation (Annex 56), 2014, Energy in Buildings and Communities Programme of the International Energy Agency, Edited by University of Minho; Guimarães, Portugal, ISBN: 978-989-95961-7-7.

[12] N. Willand, T. Moore, S. Hunter, H. Stanley, R. Horne, Drivers of Demand for Zero and Towards Zero Emissions Residential Retrofits, Australian Sustainable Built Environment Council, Melbourne, 2012

[13] UNESCO World Heritage Convention, 2013. University of Coimbra-Alta and Sofia [WWW Document]. World Heritage List. URL http://whc.unesco.org/en/ list $/ 1387 /$ multiple=1\&unique_number=1899 (accessed 29 June 2016).

[14] P. Baker, Thermal Performance of Traditional Windows (Technical Paper No. 1). Historic Scotland, Technical Conservation Group/Glasgow Caledonian University, Edinburgh, Scotland, 2010.

[15] G. Brites, N. Brito, J. Costa, A. Gaspar, M.G. da Silva, Solar cooling as an optimization of conventional solar thermal systems for existing buildings' upgrade interventions, in: Clima 2013-11th REHVA World Congress, 8th International Conference on Indoor Air Quality, Ventilation and Energy Conservation in Buildings, Prague, 2013. 